\title{
Pituitary apoplexy complicated by vasospasm and bilateral cerebral infarction
}

\author{
Giulio Gambaracci, ${ }^{1}$ Valeria Rondoni, ${ }^{1}$ Giorgio Guercini, ${ }^{2}$ Piero Floridi ${ }^{2}$
}

'Department of Radiology, Surgical and Biomedical Sciences, Division of Radiology 2, Perugia University, Perugia, Italy

${ }^{2}$ Department of

Neuroradiology, Santa Maria della Misericordia Hospital, Perugia, Italy

\section{Correspondence to}

Dr Giulio Gambaracci, giulio.gambaracci@libero.it

Accepted 8 June 2016

\section{CrossMark}

To cite: Gambaracci $G$, Rondoni V, Guercini $G$, et al. BMJ Case Rep Published online: [please include Day Month Year] doi:10.1136/ bcr-2016-216186

\section{DESCRIPTION}

Pituitary apoplexy (PA) is a clinical syndrome caused by acute haemorrhage or infarction of the pituitary gland, generally within a pituitary adenoma, and manifests as visual impairment, severe headache, meningeal irritation, consciousness disturbance and hormonal dysfunction. ${ }^{1}$ Cerebral infarction secondary to arterial vasospasm is an extremely rare complication of PA, and only a few cases have been reported. ${ }^{23}$

A 55-year-old postmenopausal woman was admitted to the emergency department, with worsening headache and decreased visual acuity. An unenhanced CT scan detected a $3 \mathrm{~cm}$ pituitary mass without signs of subarachnoid haemorrhage (SAH). Two days later, she developed fever $\left(39.1^{\circ} \mathrm{C}\right)$, and a second CT showed a larger hyperdense sellar mass, suggesting intralesional bleeding of a pituitary adenoma with secondary hypothalamus compression. Laboratory analyses revealed increased erythrocyte sedimentation rate $(64 \mathrm{~mm} /$ hour $)$ and pituitary hypofunction (table 1). The patient became lethargic, and a subsequent brain MRI examination confirmed the presence of a giant haemorrhagic sellar mass (figure 1) with mild meningeal enhancement, indicative of meningeal irritation. A focal cerebral oedema without signs of restriction was also noted in the left mesial temporal region on diffusion-weighted imaging (DWI). Trans-sphenoidal decompression and tumour

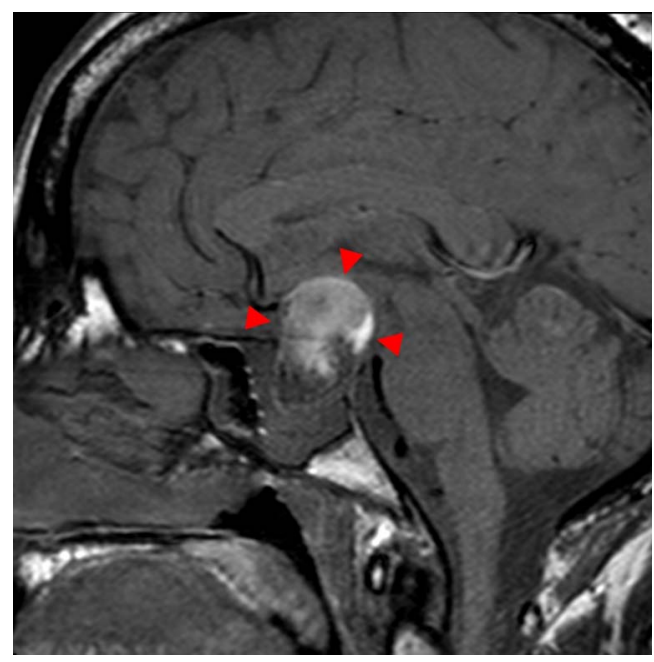

Figure 1 Sagittal section of MRI T1-weighted scan showing haemorrhagic sellar mass (red arrowheads), with suprasellar extension.

excision were performed 3 days after the diagnosis of PA. A second MRI scan (completed the same day for difficult post-operative awakening) detected bilateral extensive ischaemic lesions with DWI restriction affecting the territory of the basilar artery (right cerebellum) and middle-anterior cerebral artery (figure 2), and associated with arterial vasospasm (figure 3) without signs of SAH.

Table 1 Hormone levels

\begin{tabular}{|c|c|c|c|c|}
\hline & Acute postapoplexy (day-1) & Early follow-up* (day-7) & Late follow-upt (day-45) & Reference range \\
\hline Cortisol ( $\mu \mathrm{g} / \mathrm{dL})$ & $2.4 \downarrow$ & $140.9 \uparrow \uparrow$ & 7.6 & $6.7-22.6$ \\
\hline FSH (mUI/mL) & $2.34 \downarrow \downarrow$ & NA & NA & $18-153 \ddagger$ \\
\hline LH (mUl/mL) & $0.21 \downarrow \downarrow$ & NA & NA & $16-64 \ddagger$ \\
\hline Prolactin (ng/mL) & $1.83 \downarrow$ & NA & NA & $1.9-25.9$ \\
\hline IGF-1 (ng/mL) & 142 & NA & NA & $55-238$ \\
\hline TSH 3rd gen $(\mu U I / m L)$ & $0.17 \downarrow$ & $0.23 \downarrow$ & 0.75 & $0.34-5.60$ \\
\hline fT3 (pg/mL) & $1.95 \downarrow$ & $1.88 \downarrow$ & 2.42 & $2.35-3.77$ \\
\hline fT4 (ng/dL) & 0.59 & $0.53 \downarrow$ & 0.78 & $0.54-1.24$ \\
\hline
\end{tabular}


Figure 2 DWI and FLAIR axial sections detected extensive bilateral ischaemic lesions of the internal capsule, basal ganglia (red arrows) and right frontoinsular-temporal region $(A$, $B)$. The same features were also noted in the temporal lobe bilaterally (white arrows) and right cerebellum (red arrowheads; C,D). DWI,

diffusion-weighted imaging; FLAIR, fluid-attenuated inversion recovery.
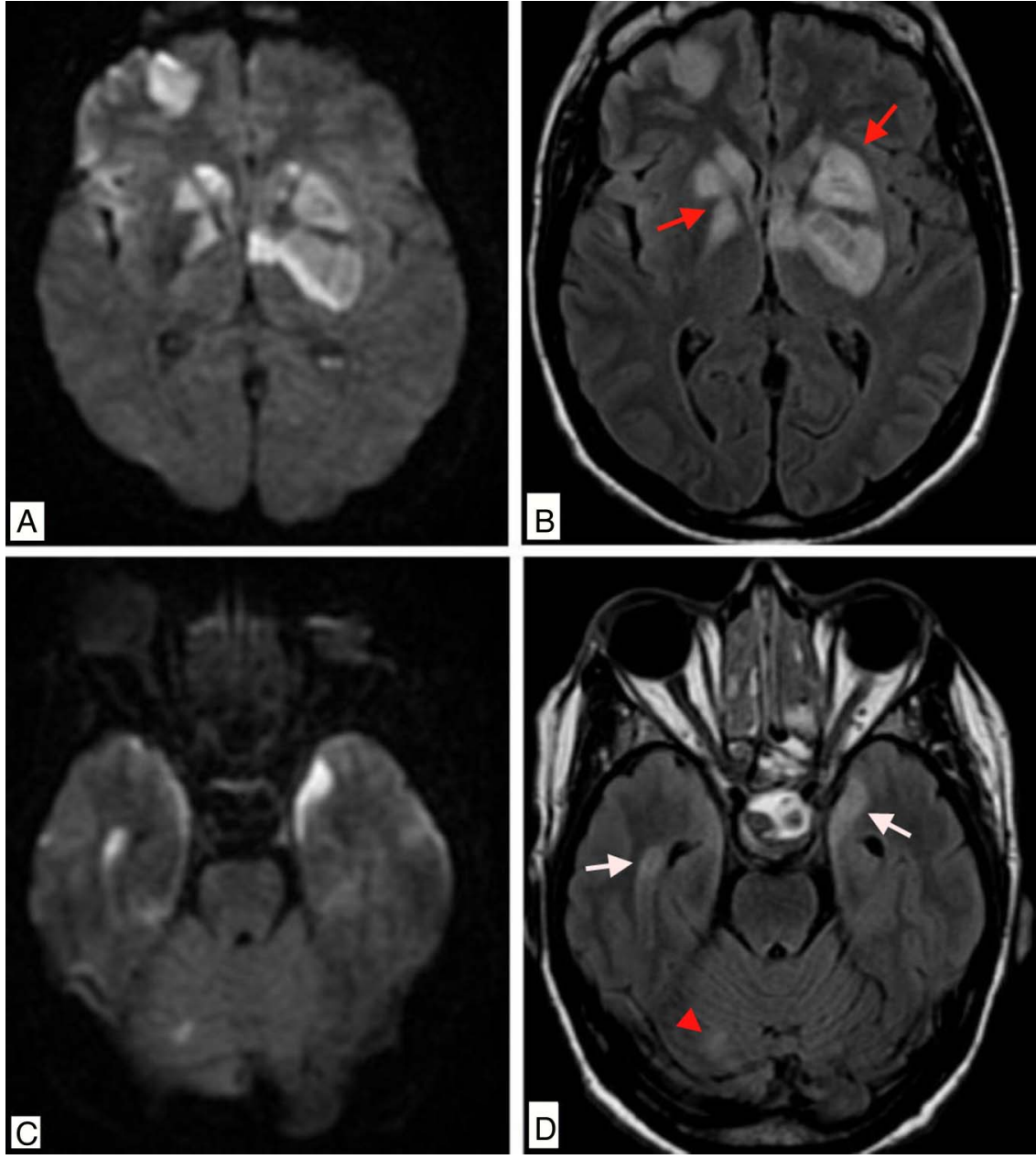

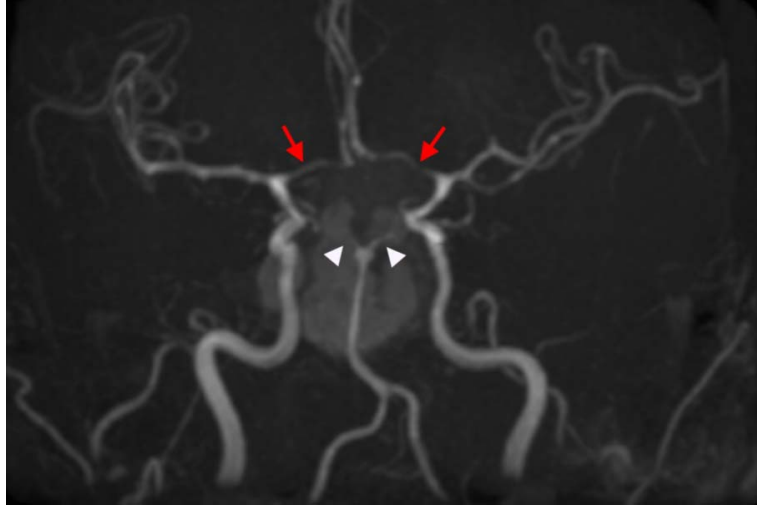

Figure 3 MR angiography showing diffuse narrowing of the bilateral intracranial arteries, especially in the anterior (red arrows) and posterior (white arrowheads) circulation.

Contributors GGa and GGu substantially contributed to the analysis and interpretation of data for the study, drafted the manuscript, approved the final version and are accountable for all aspects of the study. VR substantially contributed to the design and acquisition of data for the study, revised the manuscript, approved the final version and is accountable for all aspects of the study. PF substantially contributed to the conception and acquisition of data for the study, revised the manuscript, approved the final version and is accountable for all aspects of the study.

Competing interests None declared.

\section{Learning points}

- Bilateral cerebral infarction secondary to arterial vasospasm - even though extremely rare-should not be overlooked as a possible complication of pituitary apoplexy.

- To the best of our knowledge, the present case is one of the few reported in which ischaemic injury also affected a part of the basilar artery territory.

- Cerebral vasospasm should not be attributed solely to subarachnoid haemorrhage, as it may be related to other factors, including intraoperative arterial manipulation or the release of vasoactive substances from a haemorrhagic adenoma or a compressed hypothalamus.

Patient consent Obtained.

Provenance and peer review Not commissioned; externally peer reviewed.

\section{REFERENCES}

1 Briet C, Salenave S, Chanson P. Pituitary apoplexy. Endocrinol Metab Clin North Am 2015;44:199-209.

2 Zou Z, Liu C, Sun B, et al. Surgical treatment of pituitary apoplexy in association with hemispheric infarction. J Clin Neurosci 2015;22:1550-4.

3 Cerase A, Tarantino A, Muzii VF, et al. Vasospasm and cerebral infarction from pituitary apoplexy. A case report. Neuroradiol J 2010;23:321-4. 
Copyright 2016 BMJ Publishing Group. All rights reserved. For permission to reuse any of this content visit http://group.bmj.com/group/rights-licensing/permissions.

BMJ Case Report Fellows may re-use this article for personal use and teaching without any further permission.

Become a Fellow of BMJ Case Reports today and you can:

- Submit as many cases as you like

- Enjoy fast sympathetic peer review and rapid publication of accepted articles

- Access all the published articles

- Re-use any of the published material for personal use and teaching without further permission

For information on Institutional Fellowships contact consortiasales@bmjgroup.com

Visit casereports.bmj.com for more articles like this and to become a Fellow 